\title{
THE ISSUES OF SERVICMEN DISCIPLINE AND ADAPTACION
}

Nadoyan A. A. (Yerevan State University, Yerevan, Armenia) Minasyan G. H. (Armenian State Pedagogical University, Yerevan, Armenia) a.nadoyan@mail.ru, gayane-minasyan-1994@mail.ru

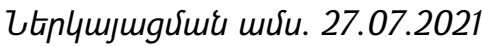

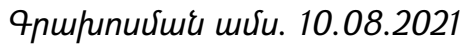

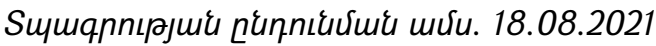

The article introduces the requirements of RA Armed Forces presented to servicemen. Discipline is the strict and mandatory maintenance of rules regulated by laws and military orders and set by the commanders. The purpose of the research is to study military discipline, the causes and effects of disorder as well as its results, since it is based on the awareness of military duty and personal responsibility of servicemen. The objectives of our planned continuous research are to observe the approaches to the issue under discussion in scholarly literature, to investigate the peculiarities of discipline and disorder among the examined servicemen, their ways of expression as well as causes and effects. The topicality of the issue is determined by the importance of the discipline of servicemen and accomplishment of the objectives mentioned above. The hypothesis of the research is that the more flexible is the adaptability of the serviceman during the military service, the more effective he is in complying with the requirements and regulations of the military service. The research has been carried out among 200 military servicemen. To investigate this issue the corresponding psychological assessments methods have been applied: test method, psychological conversation, observation and case study. $u$

Keywords: serviceman, discipline, disciplinary penalty, encouragement, adaptation.

DOI: https://doi.org/10.46991/SBMP/2022.5.1.092

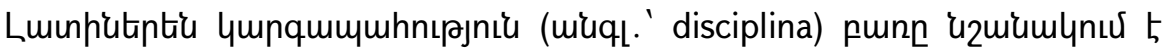

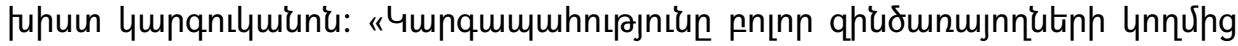

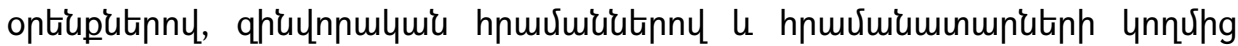

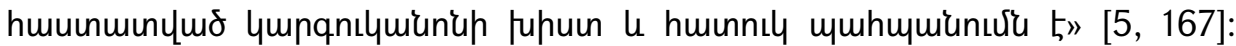

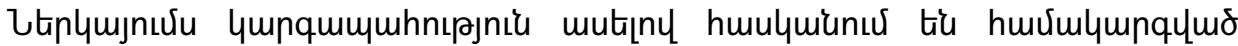

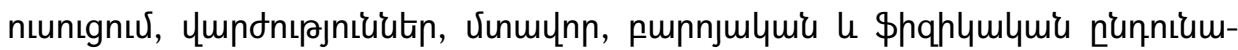

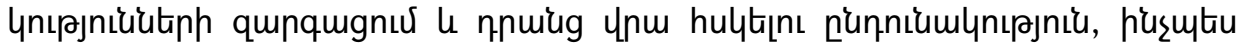

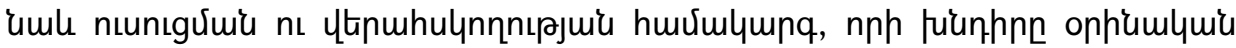

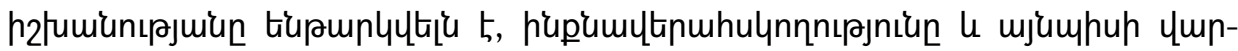

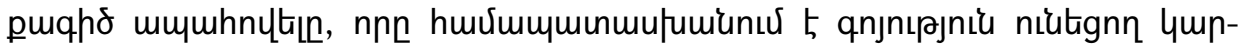




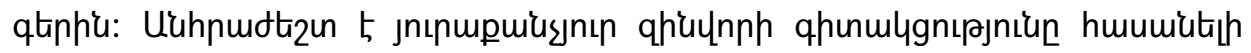

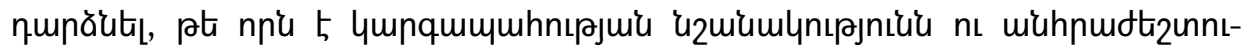

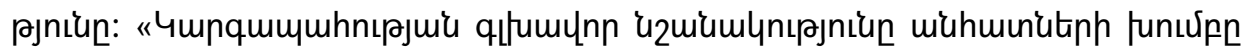

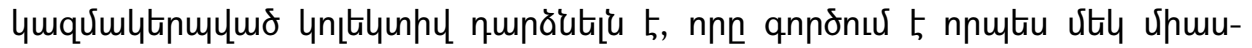

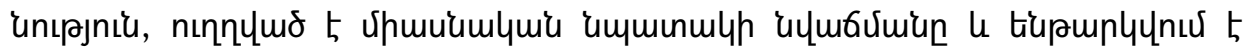

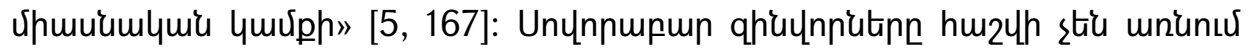

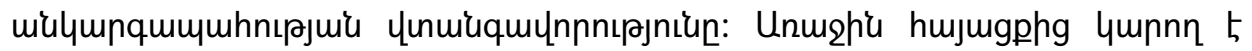

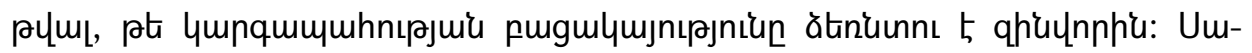

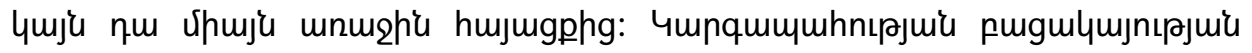

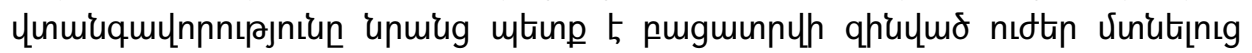

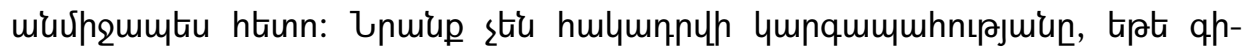

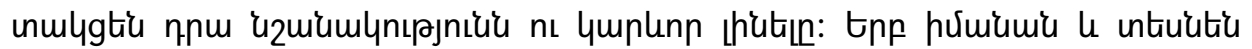

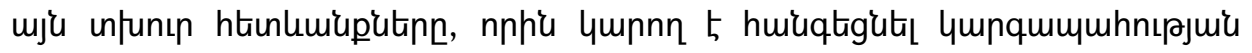

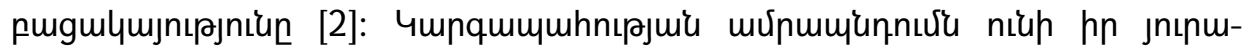

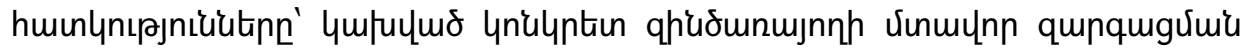

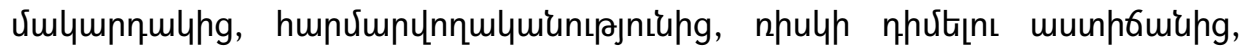

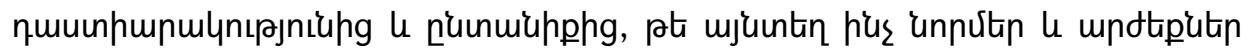

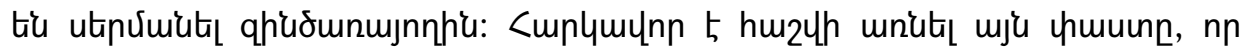

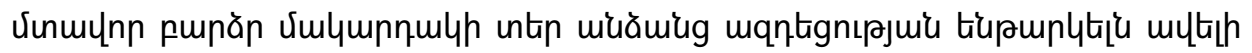

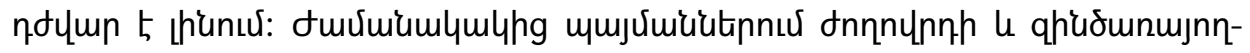

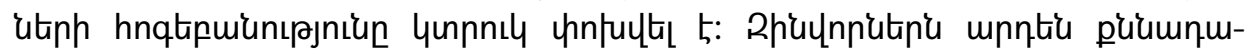

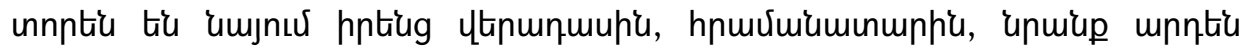

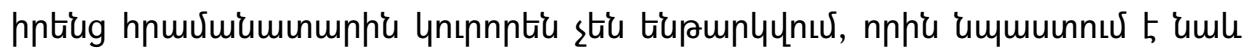

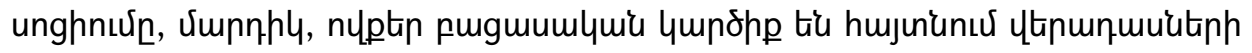

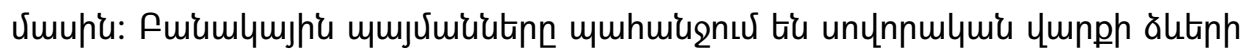

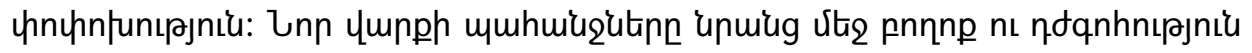

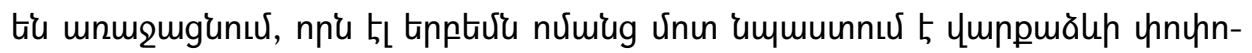

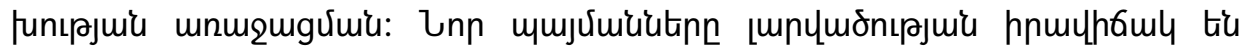

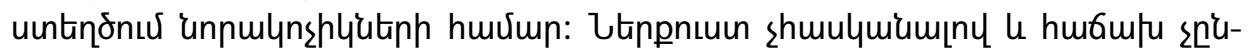

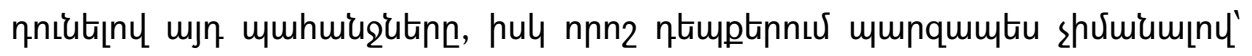

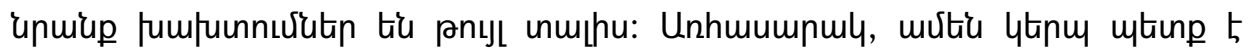

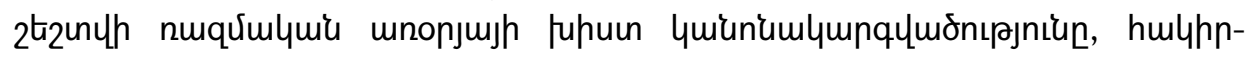

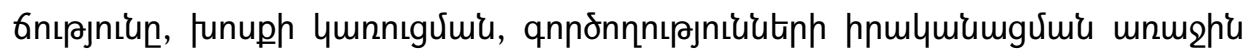

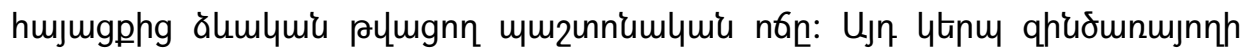

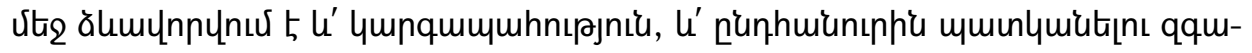

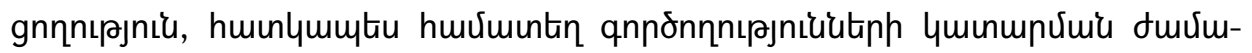

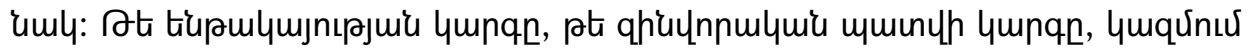

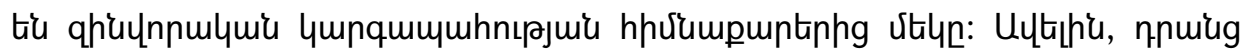

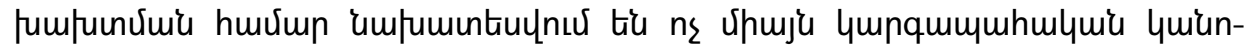




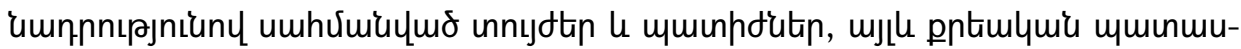
fumiumunцnıpjnıนu [4, 77]:

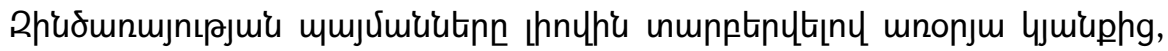

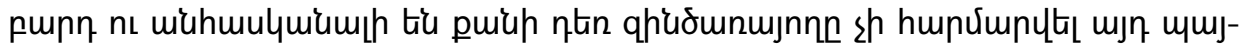

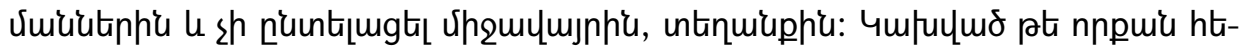

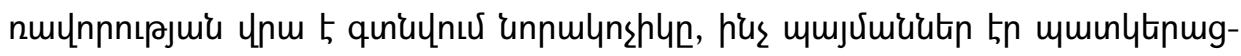

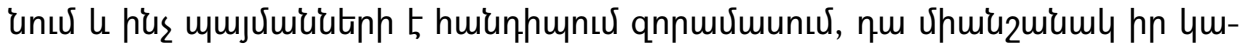

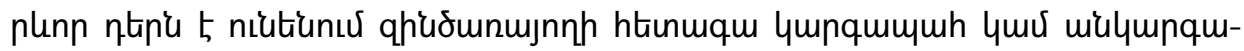

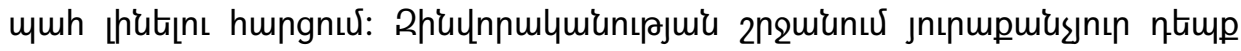

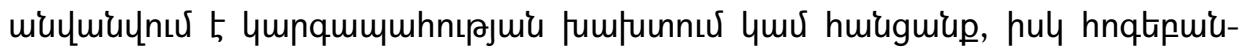

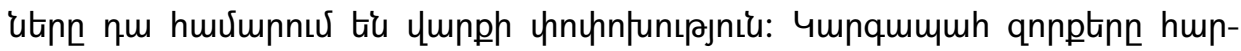

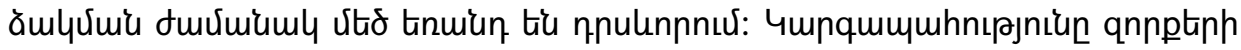

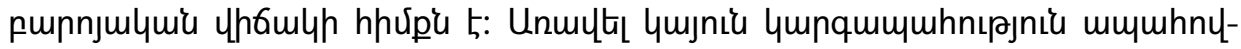

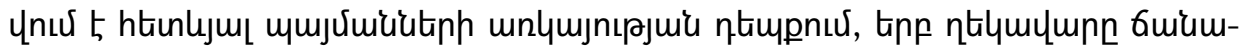

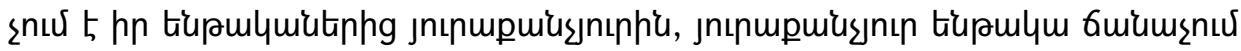

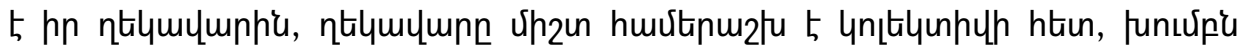

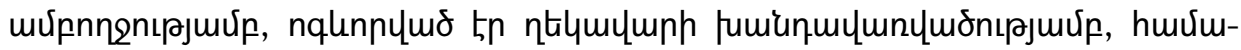

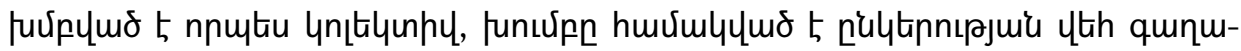

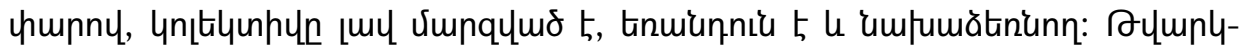

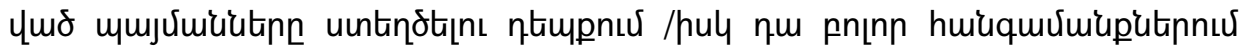

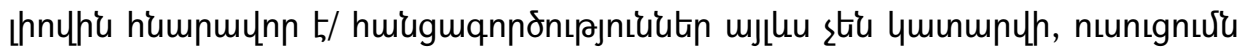

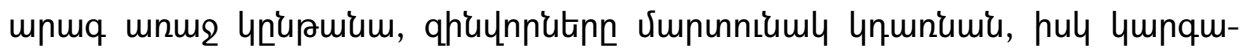

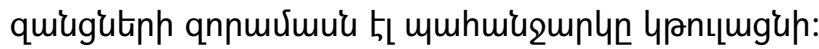

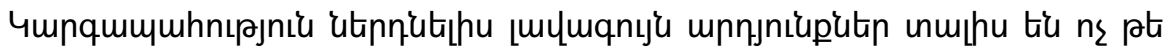

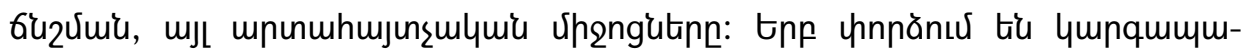

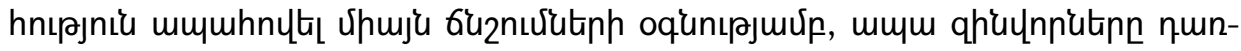

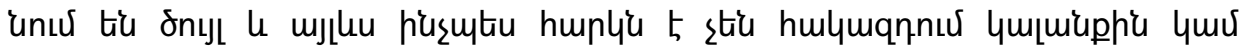

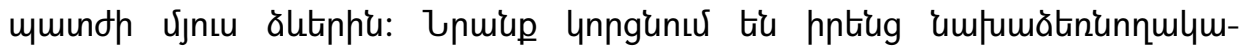

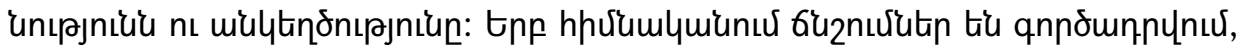

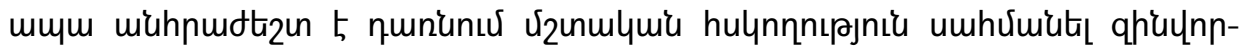

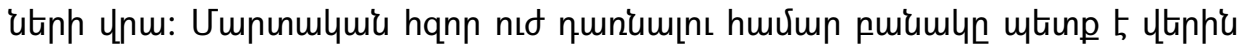

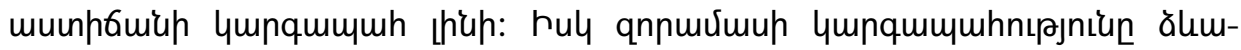

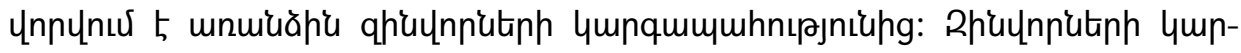

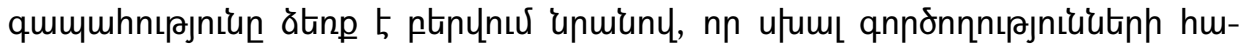

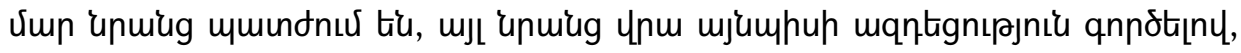

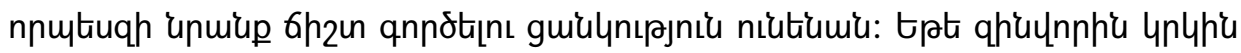

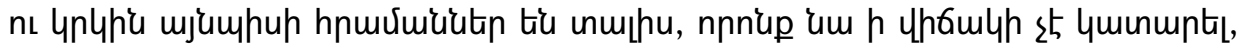

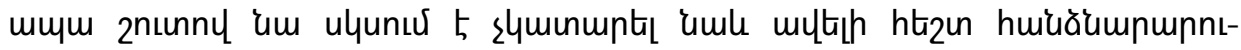

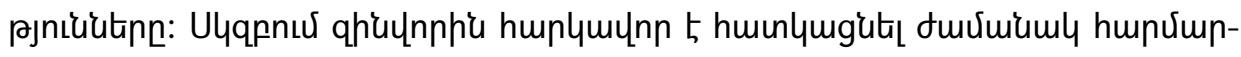

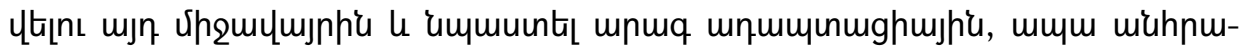




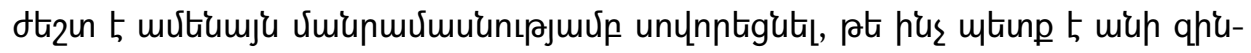

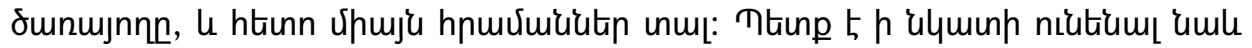

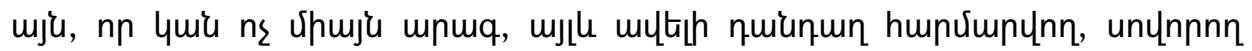

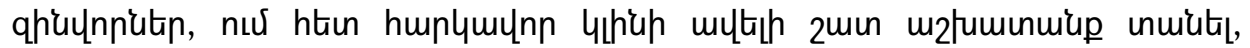

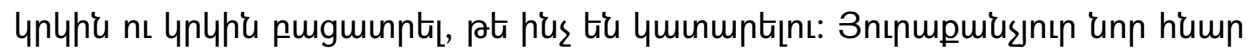

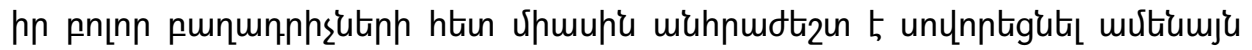

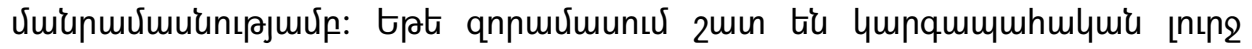

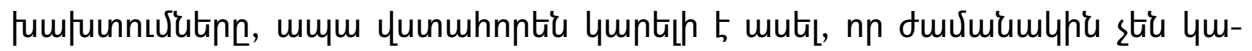

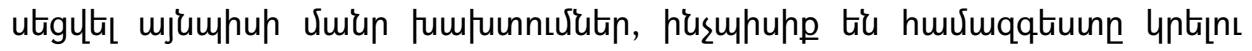

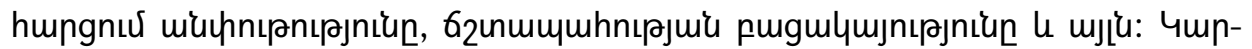

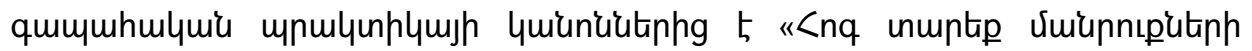

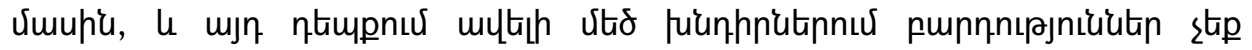

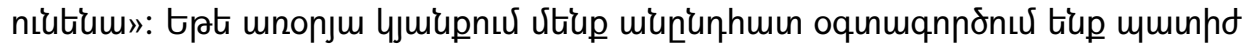

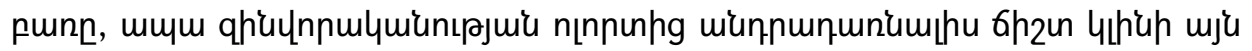

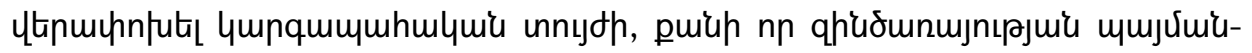

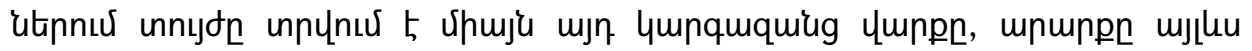

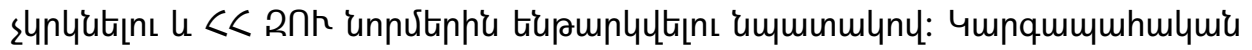

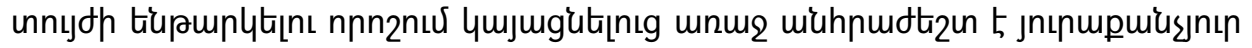

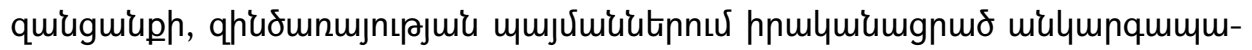

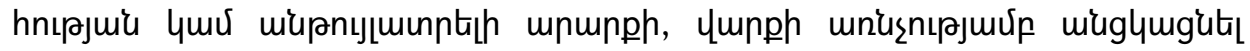

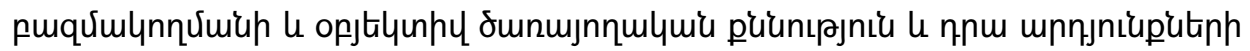

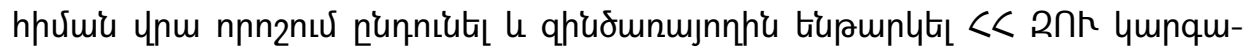

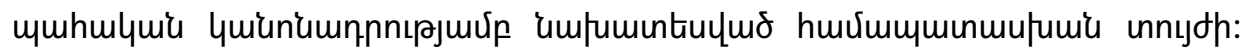

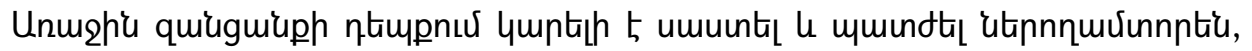

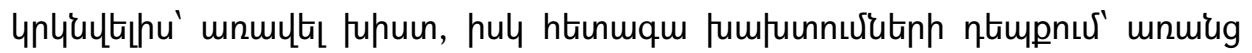

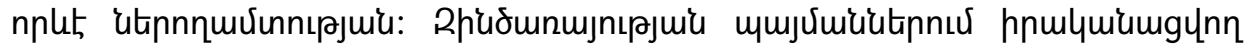

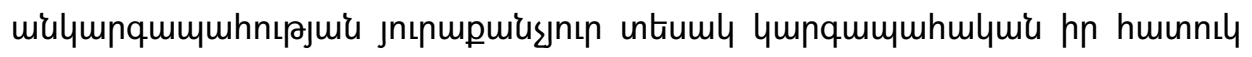

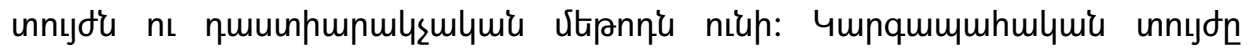

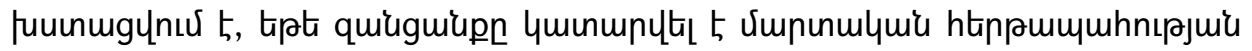

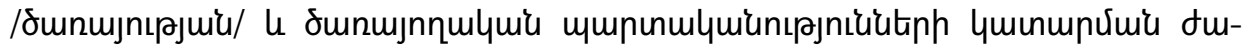

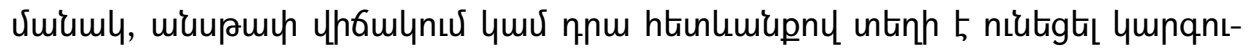
quiunah trulquiu fumfunnux [3]:

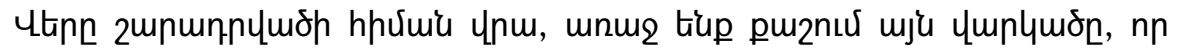

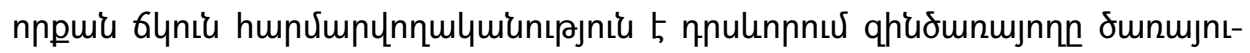

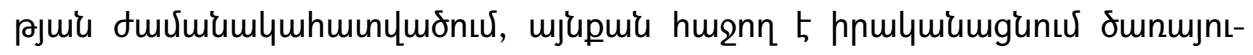

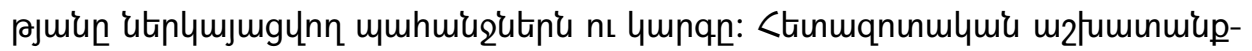

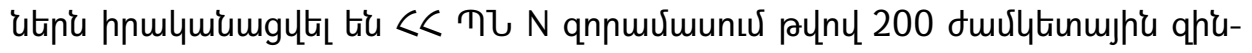

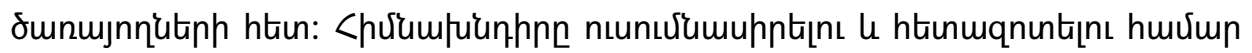

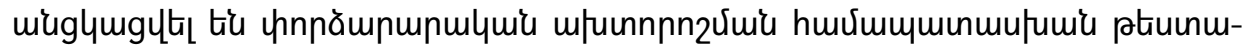

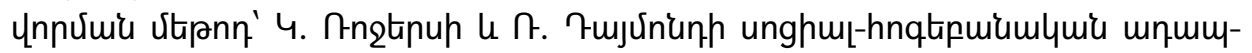




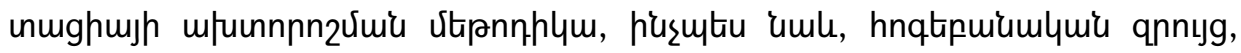

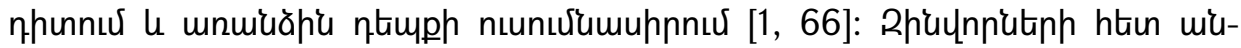

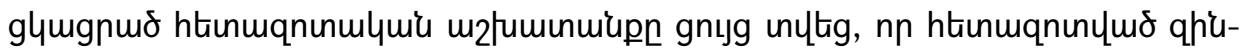

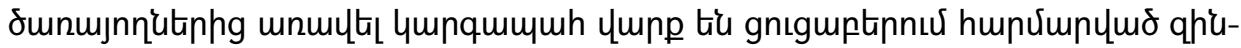

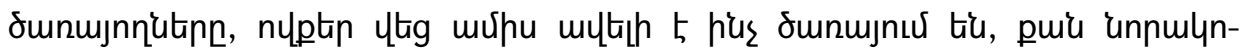

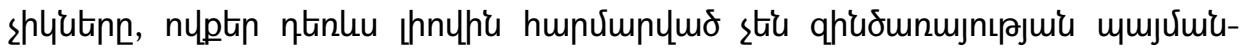

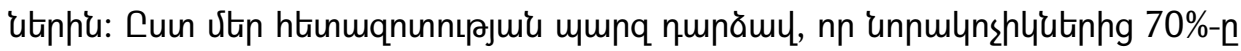

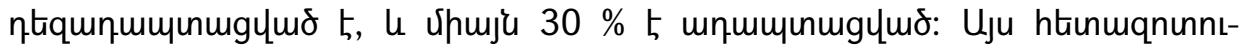

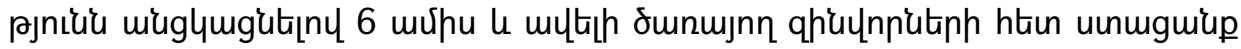

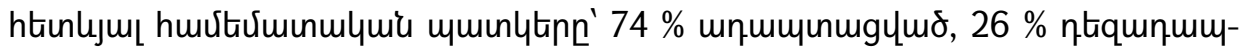

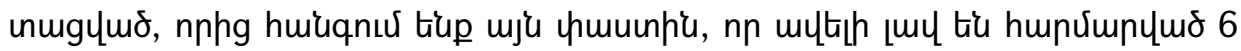

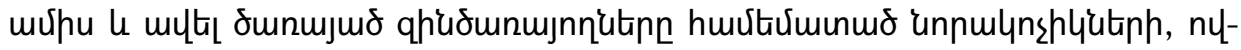

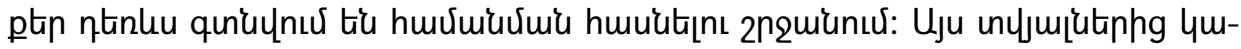

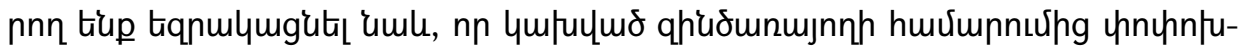

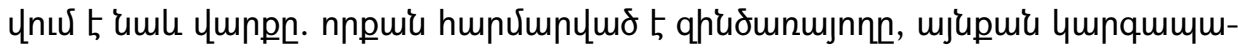

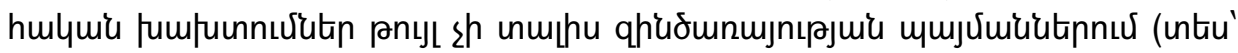
ulymp 1):

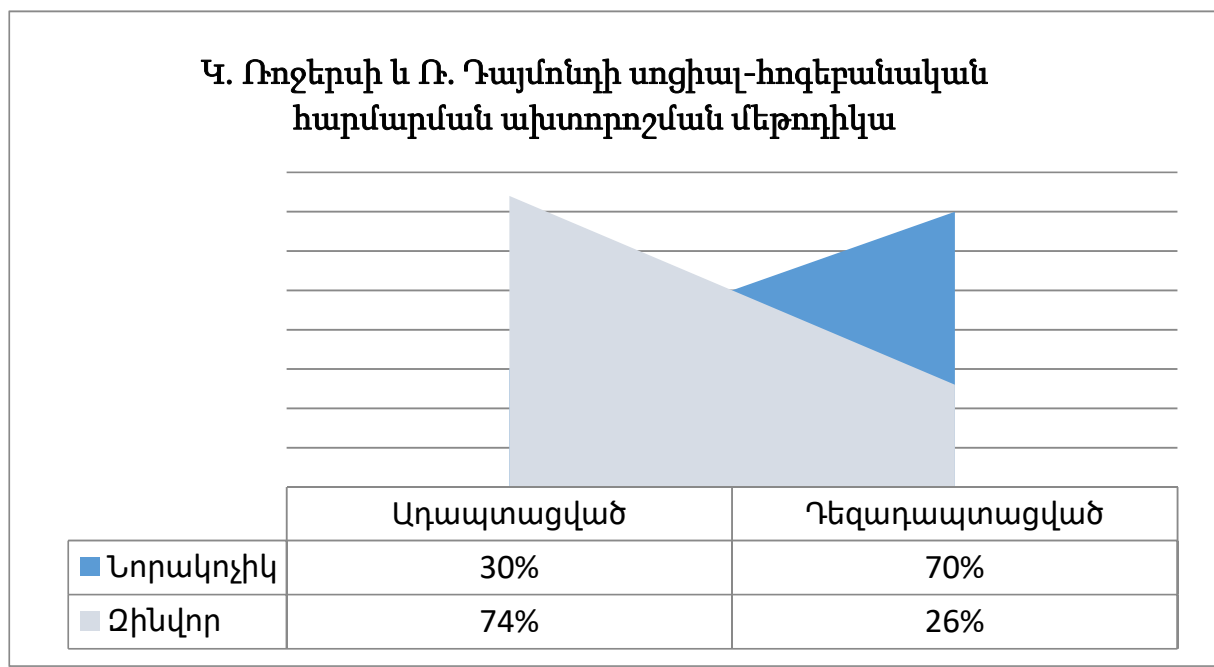

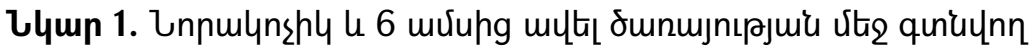

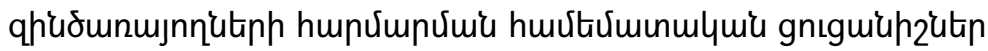

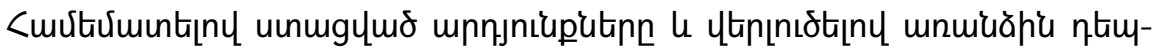

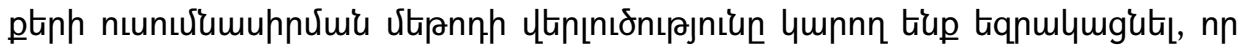

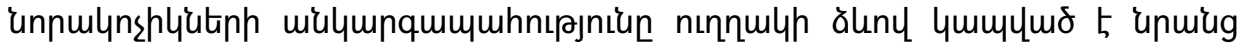

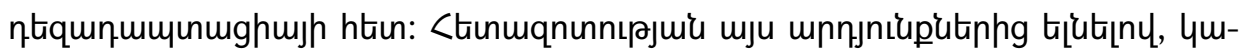

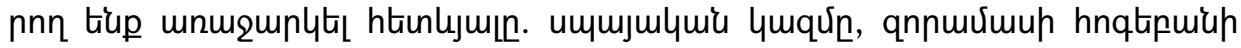




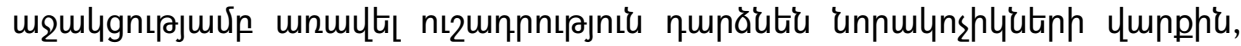

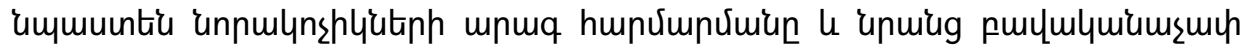

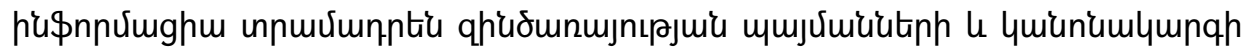

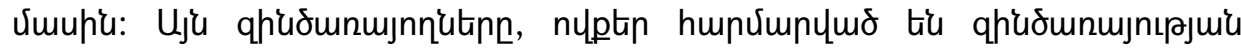

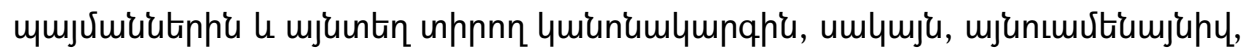

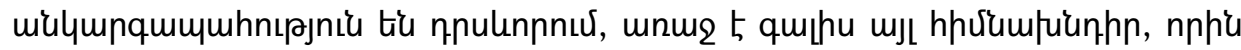

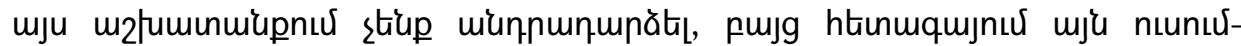
umuhnnıرuiu qunutiup:

\section{9pulquinıpjnıtu}

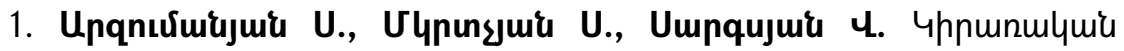

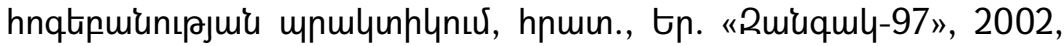
391 5.:

2. « T乙, Funnjuhnqtipuiumlyuiu mumhnunu, tp. 2015, 128 5,

3. « TU «<ujntühph umpunhl», tp. 2, 2003, 32 5q:

4. Аветисян С. С. Воинские преступления: теория и практика /отв. А. Хачатрян.- Ер.: Зангак-97, 2000.- 216 с.

5. Военный энциклопедический словарь, том 1., М. Изд. РИПОЛ КЛАССИК, 2001- 848 с.

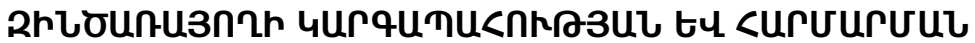

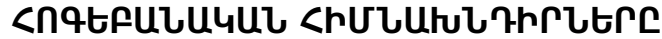

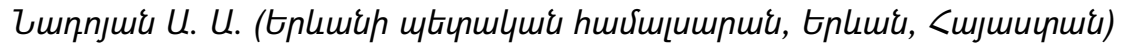

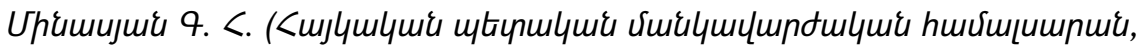
tpliши, <шјмичмиі)

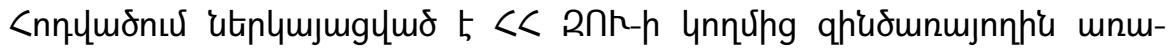

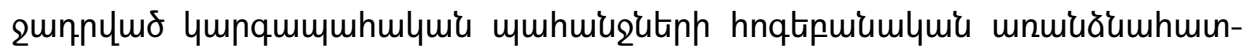

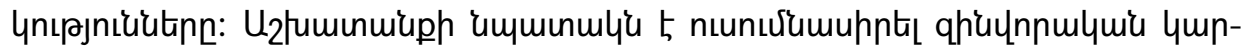

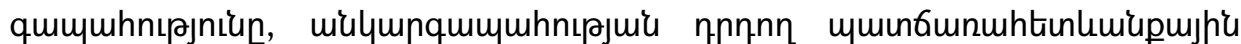

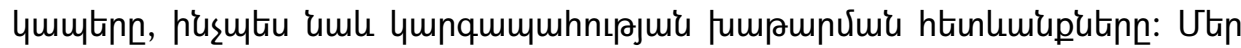

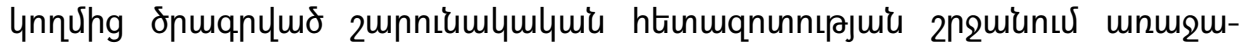

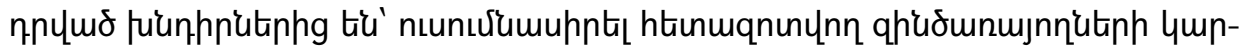

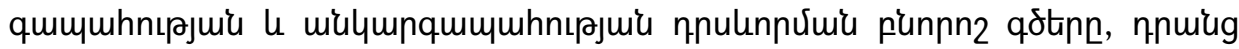

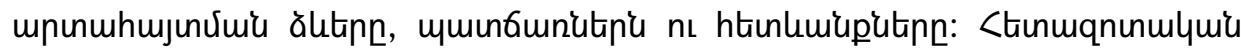

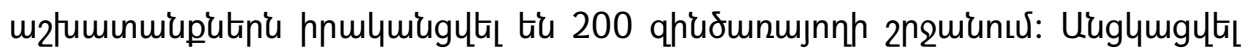

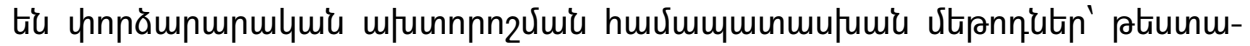

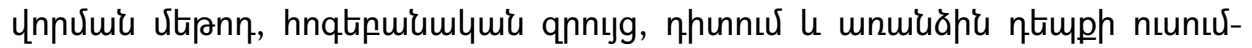
umuhnnuर (case study): 


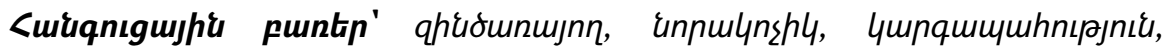

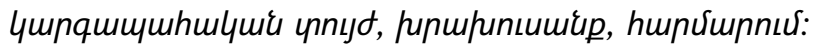

\section{ПСИХОЛОГИЧЕСКИЕ ПРОБЛЕМЫ ДИСЦИПЛИНЫ И АДАПТАЦИИ ВОЕННОСЛУЖАЩЕГО}

Надоян А.А. (Ереванский государственный университет, Ереван, Армения) Минасян Г. Г. (Армянский государственный педагогический университет, Ереван, Армения)

Актуальность исследования основана на все более нарастающем требовании государства и гражданского общества к вопросам дисциплины в действующей армии. В статье представлены психологические особенности дисциплинарных требований, предъявляемых военнослужащим в ВС РА. Дисциплина в армии основана на требованиях законов и уставов, а также на неукоснительном выполнении всех приказов командного состава. Целью работы является исследование психологических аспектов армейской дисциплины, причинно-следственные особенности, толкающие на ее нарушение. В рамках запланированного нами лонгитюдного исследования основными задачами являются: ознакомление и изучение существующих в специальной литературе материалов относительно предмета нашего исследования, анализ основных характерных черт военнослужащего дисциплинированного и недисциплинированного, а также выделение наиболее частых способов проявлений недисциплинированности, причин и последствий таковых. Гипотеза работы следующая: чем больше проявлений гибкости, приспосабливаемости в поведении военнослужащего - тем легче исполнение, предъявляемых к военнослужащему требований. В исследовании участвовало 200 военнослужащих. В процессе исследования применялись методы психологической диагностики: тестирование, беседа с психологом и case study.

Ключевые слова: военнослужащий, призывник, дисциплина, дисциплинарное взыскание, поощрение, адаптация. 